\title{
Os Graffitti de Léon-Gontran Damas
}

\author{
Marcos Bagno \\ Universidade de Brasilia
}

Léon-Gontran Damas nasceu em 28 de março de 1912, em Caiena, na Guiana Francesa. Seu pai é mestiço africano-europeu; sua mãe, africano-ameríndia. Com um ano de vida, perde a mãe. A criança, asmática e de saúde frágil, vai ser criada pela tia Grabielle Damas, apelidada "Man Gabi”, que o formará numa educação burguesa à francesa. Aos doze anos, é enviado à Martinica, uma das Antilhas francesas, para estudar no Liceu Victor Schoelcher, onde terá como colega Aimé Césaire e como professor, Gilbert Gratiant. Alguns anos depois, vai concluir seus estudos fundamentais na França. Em Paris, trava relações com Léopold S. Senghor e reencontra Aimé Césaire. Assim, surge o tripé do movimento literário e intelectual que passará a ser conhecido como Negritude.

Para Damas, a Negritude é "a tomada de consciência de um estado de coisas que se caracteriza por três elementos: a colonização, a assimilação, uma vontade de integração humana". Embora sempre mencionado com um dos três "pais fundadores" do movimento, Damas acabou por ficar marginalizado e hoje goza de uma posteridade menos brilhante que a dos outros companheiros. Talvez porque sua carreira política não tenha sido tão prestigiosa quanto a do deputado-prefeito Césaire ou do presidente Senghor. Além disso, em Paris, manteve-se afastado da revista Présence Africaine, que era o núcleo da cultura negra na capital francesa. Finalmente, sua poesia, mais bruta e rebelde, demasiado agressiva em alguns aspectos e, na aparência, mais "fácil" que a de Césaire e Senghor, não se presta tanto, talvez, à publicidade literária.

Léon-Gontran Damas é poeta da insurreição. No entanto, sua poesia também apresenta outro engajamento, o engajamento amoroso, no qual a mulher é idealizada numa tonalidade doce-amarga, às vezes com um lampejo de raiva que 
beira o escárnio. Sua obra poética inclui Pigments (1937), Graffiti (1952), Black Label (1956), Névralgie (1966). Sua produção ensaística se compilou em Retour de Guyane (1938). Em prosa, temos os contos de Veillées noires: contes nègres de Guyane (1943). Morreu em 1978.

Escolhemos traduzir alguns dos poemas curtos da série Graffiti, os quais, como indica o título da coletânea, poderiam ter sido "rabiscados num muro". Para tornar conhecido o autor, não por sua obra engajada, mas por sua poética amorosa, selecionamos, dos Graffiti, aqueles que têm por núcleo irradiador a mulher: amada, recordada, perdida, vista de passagem. São poemas de melancolia amarga ("minha aflição/de cachorro doido"), de tristeza prevista ("meu coração que se inquieta/e que já receia/um belo dia/ter de esperar-te em vão") e de impaciência ("Deus como és bela/mas/lenta para ficar nua"). A aparente simplicidade da forma e da linguagem não deve nos enganar: por trás dos versos curtos, dos poemas rápidos, pulsa uma forte tensão, característica da voz rebelde de um poeta que foi também um homem de lutas incessantes contra o racismo e o colonialismo.

\section{Graffiti}

COMO UM ROSÁRIO

COMME UN ROSAIRE

se debulha

s'égrène

para o repouso

pour le repos

de uma alma

d'une âme

minhas noites se vão

mes nuits s'en vont

de cinco em cinco

par cinq

em um silêncio

dans un silence

de mosteiro

de monastère

assombrado

hanté 
ELA VEIO

por Ela mesma

uma noite

rondar uma noite

em volta de minha aflição

de cachorro doido

de cachorro pelado

de cachorro muito cachorro

doido

pelado

Assim

sem mais

nasceu

o drama
ELLE S'EN VINT

d'Elle-même

un soir

rôder un soir

autour de ma détresse

de chien tout fou

de chien-tout-nu

de chien tout chien

tout fou

tout nu

Ainsi

sans plus

naquit

le drame 
PERDOA A DEUS QUEM SE ARREPENDE

de me ter feito

uma vida triste

uma vida rude

uma vida dura

uma vida agreste

uma vida vã

pois

na orla da mata

sob a qual nos surpreende

a noite de antes de minha

[fuga afroameríndia

te confessarei sem fardos

tudo de que em silêncio

me incriminas
PARDONNE À DIEU QUI SE REPENT

de m'avoir fait

une vie triste

une vie rude

une vie dure

une vie âpre

une vive vide

car

à l'orée du bois

sous lequel nous surprit

la nuit d'avant ma fugue

[afro-amérindienne

je t'avouerai sans fards

tout ce dont en silence

tu m'incrimines 
EM VERDADE NÃO SEI

de nada mais triste

de mais odioso

de mais horrendo

de mais lúgubre no mundo

que ouvir o amor

durante todo o dia

se repetindo

em missa

baixa

Era uma vez

veio a passar uma mulher

com os braços carregados de rosas
JE NE SAIS EN VÉRITÉ

rien de plus triste

de plus odieux

de plus affreux

de plus lugubre au monde

que d'entendre l'amour

à longueur de journée

se répétant

à messe

basse

Il était une fois

une femme vint à passer

dont les bras étaient chargés de roses 
DESEJO DE MENINO ENFERMO

por ter sido

cedo demais privado do leite puro

da única ternura verdadeira

eu teria dado

uma plena vida de homem

para te sentir

te sentir perto

perto de mim

de mim só

só

sempre perto

de mim só

sempre bela

como sabes

sabes bem

tu só

ser bela sempre

após ter chorado
DÉSIR D'ENFANT MALADE

d'avoir été

trop tôt sevré du lait pur

de la seule vraie tendresse

j’aurais donné

une pleine vie d'homme

pour te sentir

te sentir près

près de moi

de moi seul

seul

toujours près

de moi seul

toujours belle

como tu sais

tu sais si bien

toi seule

l'être toujours

après avoir pleuré 
PELA JANELA ABERTA AO MEIO sobre meu desdém do mundo uma brisa subia perfumada de estefanote enquanto puxavas para TI toda a cortina

Assim

te revejo

te reverei

sempre puxando para TI

toda a cortina

do poema onde

Deus como és bela

mas

lenta para ficar nua
PAR LA FENÊTRE OUVERTE À DEMI

sur mon dédain du monde

une brise montait

parfumée au stéphanotis

tandis que tirais à TOI

tout le rideau

Telle

je te revois

je te reverrai

toujours tirant à TOI

tout le rideau

du poème où

Dieu que tu es belle

mais

longue à être nue 
DE REPENTE NUMA CRUELDADE FINGIDA me disseste com uma voz de

[saudades feita

me disseste ao me deixar ontem me disseste que não poderias me ver antes de dez a treze dias

Por que treze

e não quinze

e não vinte

e não trinta

Por que treze

e não doze

e não oito

e não dez

e não quatro

e não dois

Por que não amanhã

a mão na mão

a mão sobre o teu

a mão sobre o meu

a mão sobre o coração

de meu coração que se inquieta

e que já receia

um belo dia

ter de esperar-te em vão
SOUDAIN D'UNE CRUAUTÉ FEINTE

tu m'as dit d'une vois de

[regrets faite

tu m'as dit en me quittant hier

tu m'as dit de ne pas pouvoir me voir avant dix à treize jours

Pourquoi treize

et pas quinze

et pas vingt

et pas trente

Pourquoi treize

et pas douze

et pas huit

et pas dix

et pas quatre

et pas deux

Pourquoi pas demain

la main dans la main

la main sur le tien

la main sur le mien

la main sur le cour

de mon cœur qui s'inquiète

et qui déjà redoute

d'avoir un beau jour

à t'attendre en vain 
QUANDO A CONTRAGOSTO

muito a contragosto penso

que no braço de um outro

dormes

então

a cabeça entre minhas mãos ardentes

então meu coração meu coração

meu pobre coração doente

então somente me dou conta

do horror

do pleno horror

da feiura

toda a feiura

de uma vida estranha e minha

paredes azuis

paredes nuas

paredes brancas de hotel cinzento

paredes nuas de hotel cinzento

cobertas do nojo de um extenuante

[tique-taque

que importa

já que

a contragosto muito a contragosto

[penso que no braço de um outro dormes

como de uma margem à outra

feliz e calma

a água dorme
QUAND MALGRÉ MOI

bien malgré je pense

qu'au bras d'un autre

tu dors

alors

ma tête entre mes mains brûlantes

alors mon cœur mon cœur

mon pauvre cœur malade

alors seulement je réalise

l'horreur

la pleine horreur

la laideur

toute la laideur

d'une vie étrange et mienne

murs bleus

murs nus

murs blancs d'hôtel gris

murs nus d'hôtel gris

qu'emplit l'écœurement d'un éreintant

[tic-tac

qu'importe

puisque

malgré moi bien malgré moi

[je pense qu'au bras d'un autre

tu dors

comme d'une rive à l'autre

heureuse et calme

l'eau dort 
FAZ JÁ

em breve

três anos

ferozmente hostil

a todo arroubo

à menor efusão

ao coração não resta

mais que comprazer-se

na rude e calma e dura

saudade de dias

que teria sido melhor

jamais numa vida de homem

ter visto luzir
DEPUIS BIENTÔT

déjà

trois ans

farouchement hostile

à tout élan

au moindre épanchement

le cœur n'a plus

qu'à se complaire

dans le rude et calme et dur

regret de jours

qu'il eût mieux valu

n'avoir jamais d'une vie d'homme

vu luire

\section{Referências bibliográficas}

ACHOUR, Christiane C. (2010). Dictionnaire des écrivains francophones classiques. Paris: Honoré Champion.

DAMAS, Léon-Gontran (1956). Black-Label et autres poème. Paris: Gallimard.

ROUCH, Alain; CLAVREUIL, Gérard (1986). Littératures nationales d'écritures française. Paris: Bordas.

JOUBERT, J.-L.; LECARME, J.; TABONE, E.; VERCIER, B. (1986). Les littératures francophones depuis 1945. Paris: Bordas. 